\title{
Impressão molecular: uma estratégia promissora na elaboração de matrizes para a liberação controlada de fármacos
}

\author{
Eduardo Costa Figueiredo*, Ana Cristi Basile Dias, Marco Aurélio Zezzi Arruda \\ Departamento de Química Analítica, Instituto de Química, Universidade Estadual de Campinas
}

*Correspondência:

E. C. Figueiredo

Departamento de Química Analítica

Instituto de Química

Cidade Universitária Zeferino Vaz

Caixa Postal 6154

13084-862 - Campinas - SP, Brasil

E-mail: eduardocfig@yahoo.com.br
As interações biomoleculares (antígeno-anticorpo, enzima-substrato e fármaco-receptor) há muito tempo têm despertado o interesse de diversos pesquisadores quanto à sua natureza seletiva. Nesse contexto, principalmente a partir de 1940, observa-se uma crescente busca por materiais sintéticos dotados de sitios seletivos de reconhecimento. Hoje, esses materiais encontram-se bem estabelecidos em diversas áreas da ciência como farmácia, química analítica, bioquímica, dentre outras, e são rotineiramente intitulados como polimeros impressos molecularmente (molecularly imprinted polymers-MIP). Embora sua maior aplicação esteja voltada às técnicas de extração/separação, alguns trabalhos têm empregado os MIP como matrizes em sistemas de liberação controlada de fármacos (drug delivery system-DDS), devido ao caráter promissor de tal aplicação e pela facilidade de obtenção desses materiais. Entretanto, o emprego clínico de MIP como DDS ainda é inexistente em decorrência de sua recente aplicação e também pelos extensivos testes que precedem a aprovação de um novo sistema de liberação controlada de fármaco. O objetivo deste trabalho é apresentar os mais recentes avanços no emprego de MIP como DDS reforçando os aspectos mais significativos dessa aplicação, bem como classificando e detalhando esses sistemas quanto aos mecanismos pelos quais o fármaco é liberado.
Unitermos

- Polímeros impressos molecularmente

- Sistemas de liberação controlada

\section{INTRODUÇÃO}

O sucesso das terapias medicamentosas é alcançado não somente pela farmacodinâmica adequada da molécula, mas, também, pela manutenção da dose efetiva do fármaco nos locais de ação. A maioria dos fármacos, com destaque para aqueles estruturalmente específicos, tem uma faixa de concentração que define os níveis de segurança e eficácia. Concentrações abaixo ou acima dessa faixa podem causar ineficiência do tratamento, além de graves efei- tos tóxicos ou sintomas anteriormente não evidenciados (Kaparissides et al., 2006). Assim, vários dispositivos têm sido propostos com o objetivo de manter (em níveis terapêuticos) a concentração do fármaco por maiores períodos de tempo, promovendo maior adesão ao tratamento, aumento nos intervalos de administração, diminuição dos efeitos colaterais, dentre outras vantagens (AlvarezLorenzo, Concheiro, 2004; Azevedo, 2002). Tal estratégia, comumente chamada de sistemas de liberação controlada de fármacos (drugs delivery systems-DDS), requer uma 
ampla interdisciplinaridade, envolvendo conhecimentos principalmente das áreas de ciências farmacêuticas, ciência de polímeros, química de colóides, físico-química e biologia molecular (Kaparissides et al., 2006).

Os diversos dispositivos empregados como DDS, podem ser classificados como sistemas reservatórios (e.g. lipossomas, nanocápsulas, fibras ocas), em que o fármaco se encontra aprisionado no interior de uma barreira de difusão inerte, e como sistemas matriciais (e.g. nanoesferas poliméricas), em que o fármaco é disperso em um polímero inerte, formando um sólido monolítico homogêneo (Duran, Azevedo, 2007). A liberação do fármaco pode ocorrer por difusão gradativa através da matriz (sistema reservatórios) ou pela degradação da matriz (sistemas matriciais) mediante algum estímulo químico ou físico, tais como mudança de $\mathrm{pH}$, força iônica e temperatura (Chien, Lin, 2002).

Embora tenha sido dado grande destaque a alguns DDS específicos (e.g. lipossomas, nanopartículas), cabe ressaltar a importância da avaliação de novos materiais na busca por sistemas mais eficientes e que apresentem menor risco ao paciente. Assim, os polímeros oriundos de impressão molecular enquadram-se perfeitamente nesse perfil e seu potencial como DDS tem sido atualmente avaliado.

A impressão molecular é uma tecnologia capaz de produzir polímeros dotados de sítios específicos de reconhecimento, estereoquimicamente moldados a partir de molécula modelo - MM (e.g. fármaco de interesse) (Magalhães et al., 2007). Nesses polímeros, rotineiramente intitulados de polímeros impressos molecularmente (molecularly imprinted polymers-MIP), a etapa de síntese (Figura 1) ocorre após a formação de um complexo entre os monômeros funcionais (MF) e a MM (Allender et al., 2000; Chien, Lin, 2002). Assim, as terminações ligantes dos MF são posicionadas em pontos complementares àqueles provenientes da $\mathrm{MM}$, permitindo a formação de ligações e, como conseqüência, uma notável capacidade enantiosseletiva (Hilt, Byrne, 2004).

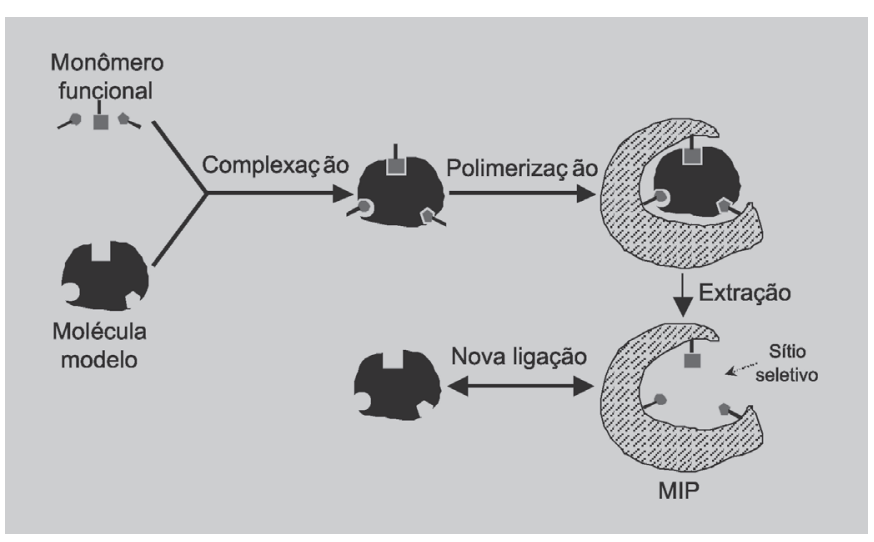

FIGURA 1 - Esquema genérico da síntese do MIP.
Embora os MIP despontem como uma tendência promissora em DDS, o número de trabalhos sobre o assunto ainda é pequeno quando comparado à utilização dos mesmos em outras áreas, como em química analítica. Por outro lado, é importante ressaltar o futuro promissor dessa aplicação, corroborando as expectativas de vários grupos de pesquisa que atualmente direcionam seus esforços no desenvolvimento e melhoria de DDS. Sendo assim, o objetivo desta revisão é apresentar os avanços mais recentes no emprego de MIP como DDS, reforçando os aspectos mais significativos dessa aplicação, bem como classificando e detalhando esses sistemas quanto aos mecanismos pelos quais o fármaco é liberado. Além disso, são apresentadas algumas tendências com base na perspectiva de vários autores, bem como pelas características promissoras que direcionam os MIP no campo de DDS.

\section{HISTÓRIA DOS MIP}

A natureza das interações biomoleculares (e.g. enzimasubstrato, fármaco-receptor e antígeno-anticorpo) sempre despertou interesse dos pesquisadores no tocante aos fenômenos que regem a manifestação da resposta biológica e aos fatores responsáveis pela seletividade inerente a tais interações. Tal interesse foi certamente influenciado por três fatos memoráveis da história da ciência: 1) a primeira teoria sobre as enzimas de Berzelius (1835), 2) a teoria dos receptores de Ehrlich (Limbird, 2004) e 3) a teoria de formação dos anticorpos de Pauling (1940). Nessa última, Pauling preconizava que o antígeno se portava como uma MMe os anticorpos eram modelados ao redor dessa molécula, gerando configurações complementares altamente seletivas (Pauling, 1940). Fundamentado nas notáveis idéias de seu mestre, Dickey (1949) sintetizou um adsorvente seletivo para molécula específica. A partir daí, tornou-se de grande interesse elaborar materiais com seletividade atribuída principalmente à sua estrutura tridimensional complementar a da MM. Em 1972, Wulff e Sarhan (1972) sintetizaram um polímero orgânico enantioseletivo para ácido glicérico, em que as interações entre tal molécula e os MF eram de natureza covalente. A principal característica desses polímeros era sua alta seletividade, como conseqüência da boa interação entre os MF e a MM. Contudo, cabe ressaltar que o processo de retirada da MM do sítio de ligação mostrou-se difícil, sendo necessário, em alguns casos, o emprego de condições drásticas de hidrólise. Na década de 1980, Arshady e Mosbach (1981) reportaram o primeiro artigo sobre um MIP que interagia com a MM por meio de ligações não-covalentes, permitindo que o processo de desligamento fosse suscetível a fatores como modificação do $\mathrm{pH}$, força iônica, solvente, dentre outros. Por fim, Whitcombe et al. (1995) propuseram um novo MIP, onde a MM e o MF interagiam por ligações covalentes no momento da síntese e, 
por ligações não-covalentes no momento de re-ligação (outras ligações da MM com o sítio do MIP). Após a síntese, era necessária uma hidrólise para a retirada da MM do sítio do MIP, permanecendo, nesse local, grupos ligantes capazes de interagir não-covalentemente com a $\mathrm{MM}$ em futuras interações. Dessa forma, foi possível associar as vantagens inerentes às metodologias de síntese covalente e não-covalente.

A partir da década de 1990, observou-se um aumento exponencial do número de trabalhos sobre MIP (Figura 2), denotando sua importância em diversas áreas da ciência, com desataque para a química analítica, bioquímica e ciências farmacêuticas.

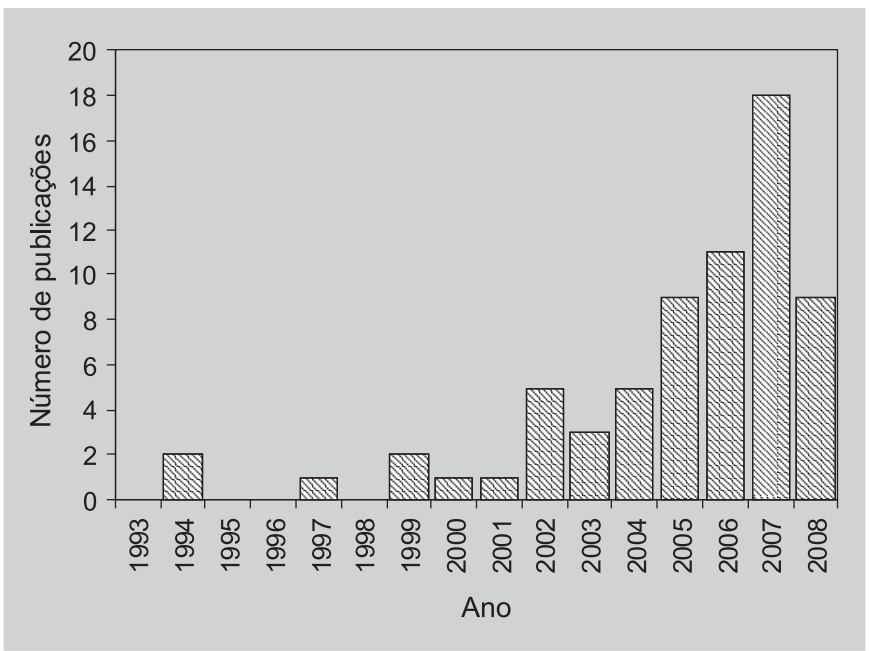

FIGURA 2 - Número de publicações científicas sobre MIP usados como DDS a partir de 1993. Fonte: Web of Science. Dia da pesquisa: 02-07-2008. Palavras-chave: drug* deliver* and molecular* imprint*.

\section{SÍNTESE DOS MIP}

Inicialmente, é interessante destacar que poucos trabalhos relatam procedimentos de síntese de MIP destinados a DDS, devido à precocidade dessa aplicação. Entretanto, ressalta-se que esses procedimentos podem ser espelhados naqueles destinados à síntese de MIP para técnicas de extração/separação, devido à grande similaridade experimental dos mesmos. Assim, a seguir, é apresentada uma revisão geral sobre a síntese de MIP (destinados a DDS ou extração/separação), com base em artigos científicos publicados a partir da década de 1990 .

\section{Metodologias de síntese}

\section{Polimerização em bulk}

Nessa metodologia de síntese, a MM e o MF são dissolvidos em um solvente apropriado e se ligam estrategica- mente em posições específicas e complementares (Figura 1). Posteriormente, adiciona-se o agente de ligação cruzada (ALC) responsável pela interligação entre as moléculas de MF, o que resulta na formação de uma rede polimérica, e o iniciador radicalar (IR), com a função de gerar radicais reativos para iniciar e sustentar a reação de polimerização. Com relação à constituição física dos MIP, salienta-se que a síntese por bulk resulta em polímeros de consistência rígida e heterogênea, sendo necessário proceder a moagem e o peneiramento do mesmo antes do uso. No primeiro trabalho sobre polimerização em bulk, Sellergren et al. (1988) sintetizaram um MIP para derivados de L-fenilalanina $(1,5 \mu \mathrm{mol})$ usando acetonitrila $(8,2 \mathrm{~mL})$ como solvente, ácido metacrílico $(6 \mu \mathrm{mol})$ como $\mathrm{MF}$, etilenoglicol dimetacrilato $(28 \mu \mathrm{mol})$ como ALC e azobisisobutironitrila $(0,4 \mu \mathrm{mol})$ como IR. A síntese ocorreu na faixa de temperatura de 60 a $120^{\circ} \mathrm{C}$ por $24 \mathrm{~h}$. Posteriormente, o MIP foi moído e lavado com acetonitrila para retirada da $\mathrm{MM}$ e dos reagentes remanescentes da síntese. Destaca-se o grande número de trabalhos que empregam essa metodologia de síntese (Philip et al., 2007; Khajeh et al., 2007; Puoci et al., 2007).

\section{Polimerização por suspensão}

Essa metodologia tem como objetivo a obtenção de microesferas com maior homogeneidade de tamanho. Os reagentes da síntese (MF, MM, ALC e IR) são dissolvidos em solvente orgânico e, em seguida, adicionados em uma fase dispersiva (normalmente polar), formando uma emulsão (com a fase apolar no interior da micela) normalmente estabilizada pelo emprego de um tensoativo. A emulsão é agitada e colocada em banho-maria (em torno de $50{ }^{\circ} \mathrm{C}$ ) para ocorrer a polimerização. Durante esse processo, as partículas do MIP vão sendo formadas na fase interna da emulsão (reagentes de síntese e solvente orgânico), permanecendo em suspensão com a fase dispersiva (Wang et al., 2006; Haginaka, 2008; Jantarat et al., 2008). Matsui et al. (1997) empregaram água como fase dispersiva e um polímero de polivinil álcool como tensoativo na obtenção de microesferas de MIP seletivas- a atrazina (7,3 mmol foram usados na síntese). Clorofórmio $(30 \mathrm{~mL})$, ácido metacrílico (73 mmol), etilenoglicol dimetacrilato (207 mmol) e azobis-(dimetilvarelonitrila) $(0,94 \mathrm{~g})$ foram empregados como solvente, MF, ALC e IR, respectivamente. A síntese ocorreu por $6 \mathrm{~h}$ a $50^{\circ} \mathrm{C}$, seguida de $15 \mathrm{~h}$ à temperatura ambiente. Entretanto, ressalta-se que a água usada com fase dispersiva pode trazer problemas relativos à má formação dos sítios seletivos do MIP, por competir com a MM pelas ligações com o MF. Dessa forma, outras fases dispersivas têm sido usadas como, por exemplo, um tensoativo de aspecto pastoso a base de polímero de perfluorocarbono (Mayes, Mosbach, 1996). 


\section{Polimerização por enxerto}

Essa metodologia emprega um suporte polimérico (polímero de trimetilolpropano) com poros esféricos (5 a $10 \mathrm{~mm}$ ) como base para síntese do MIP. Os reagentes (MF, MM, ALC e IR) são dissolvidos no solvente e adicionados no suporte polimérico até o preenchimento dos poros do mesmo. Em seguida, a mistura é degaseificada e a síntese é conduzida à temperatura de $60^{\circ} \mathrm{C}$ por $4 \mathrm{~h}$. Após a síntese, a adição de água, seguida de forte agitação, faz com que as microesferas do MIP sejam suspensas. Estas são coletadas (sobrenadante), lavadas e usadas nos experimentos de seletividade (Yilmaz et al., 2002; Wolman et al., 2006). No primeiro trabalho sobre a polimerização por enxerto, Glad, Reinholdsson e Mosbach (1995) relatam a síntese de microesferas de MIP seletivas a $t$-butiloxicarbonil fenilalanina (264 mg), usando clorofórmio (6 mL), ácido metacrílico $(3,5 \mu \mathrm{mol})$, etilenoglicol dimetacrilato $(1,4 \mathrm{a}$ $15,0 \mu \mathrm{mol}), 2,2$-azobisisobutironitrila $(0,2 \mu \mathrm{mol})$ como solvente, MF, ALC, IR, respectivamente. Após a síntese adicionaram-se $100 \mathrm{~mL}$ de água e as microesferas foram suspensas, separadas e lavadas (tolueno, etanol e acetona). Os autores destacam a maior facilidade no procedimento de síntese e a homogeneidade de tamanho das partículas como principais vantagens da polimerização por enxerto em comparação à polimerização em bulk. Por outro lado, observouse que a enantiosseletividade foi semelhante para MIP obtidos pelas duas metodologias de síntese (Glad, Reinholdsson, Mosbach, 1995).

\section{Polimerização por precipitação}

Essa metodologia é semelhante à polimerização em bulk, a não ser pelos grandes volumes de solventes (5 vezes maior) empregados na dissolução dos reagentes (MF, MM, ALC e IR). Essa mistura (reagentes e solvente) é degaseificada e acondicionada em banho-maria à temperatura de $60^{\circ} \mathrm{C}$ por $24 \mathrm{~h}$. A polimerização inicia-se de maneira pontual e o crescimento do MIP resulta da captura de oligômeros nascentes presentes na solução. A precipitação ocorre quando a microesfera adquire densidade maior que a solução (Pouci et al., 2004; Ciardelli et al., 2004; Ulubayram, Tunc, Baykara, 2007). Yoshimatsu et al. (2007) sintetizaram um MIP seletivo para propranolol por meio de polimerização por precipitação. A síntese foi feita empregando-se propranolol $(0,5 \mu \mathrm{mol})$ como $\mathrm{MM}$, acetonitrila $(40 \mathrm{~mL})$ como solvente, ácido metacrílico $(1,3 \mu \mathrm{mol})$ como MF, divinilbenzeno $(5,2 \mu \mathrm{mol}) \mathrm{e}$ azobisisobutironitrila como IR. A solução foi degaseificada e polimerizada $\left(60{ }^{\circ} \mathrm{C}\right.$ por $\left.24 \mathrm{~h}\right)$. Após a síntese, as microesferas foram separadas por centrifugação e lavadas (metanol:ácido acético). Os autores ressaltam que a principal vantagem desse procedimento foi a formação de microesferas altamente homogêneas sem a necessidade da formação de emulsões notadamente incompatíveis com algumas MM.

\section{Variáveis experimentais}

A síntese de um MIP está sujeita a diversas variáveis experimentais como a natureza e concentração da MM, do MF, do ALC e do IR (Cormack, Elorza, 2004). Neste contexto, algumas regras inerentes a essas variáveis podem ser relatadas com o objetivo de auxiliar os processos de síntese de novos MIP. Entretanto, essas regras nem sempre são garantia de formação eficiente de sítios específicos de reconhecimento, sendo realmente necessário o estudo individual dessas variáveis no que se refere à busca por seletividade.

\section{Molécula modelo}

Inicialmente, a MM deve ser avaliada quanto à presença de grupos capazes de se ligar aos MF. Por outro lado, essa molécula não deve possuir grupos que acelerem ou retardem a reação de polimerização (como, por exemplo, o grupo tiol), bem como grupos polimerizáveis que certamente promoverão sua inserção dentro da rede polimérica e, conseqüentemente, a não formação dos sítios de reconhecimento (Cormack, Elorza, 2004). Por fim, as MM devem ser estáveis a temperaturas de aproximadamente $60{ }^{\circ} \mathrm{C}$, caso a 2,2'-azobisisobutironitrila for empregada como IR (Cormack, Elorza, 2004).

\section{Monômero funcional}

Na maioria dos casos emprega-se um MF doador de próton (caráter ácido), quando a MM é aceptora de próton (caráter básico), ou vice-versa (Tarley, Sotomayor, Kubota, 2005). Assim, o ácido metacrílico e a 4-vinilpiridina são os mais usados na síntese de MIP para moléculas básicas e ácidas, respectivamente. Entretanto, outros MF (Tabela I) podem ser usados resultando em diferentes tipos de interação com a MM (Tarley, Sotomayor, Kubota, 2005). Em termos de concentração, o mais indicado é que o MF esteja em quantidade superior à MM (normalmente 4:1-fração molar), garantindo, assim, o deslocamento do equilíbrio para a formação do maior número possível de sítios específicos (Andersson, Sellergren, Mosbach, 1984; Martín-Esteban, 2001). Finalmente, é importante destacar que uma combinação de MF de natureza ácida e básica pode resultar em MIP mais seletivos (Ramström, Andersson, Mosbach, 1993). Entretanto, a proporção molar deve ser bem avaliada a fim de assegurar rigidez, porosidade e estabilidade mecânica ao MIP (Ramström, Andersson, Mosbach, 1993). 
TABELA I - Monômeros funcionais comumente empregados na síntese de MIP

\begin{tabular}{|c|c|c|}
\hline Monômero funcional & Estrutura química & Tipo de interação com o analito \\
\hline Ácido acrílico & & Iônica e ligação de hidrogênio \\
\hline Ácido metacrílico & & Iônica e ligação de hidrogênio \\
\hline Ácido $p$-vinilbenzóico & & Iônica e ligação de hidrogênio \\
\hline Ácido acrilamidossulfônico & & iônica \\
\hline Amino metacrilamida & $\mathrm{NR}_{2}$ & iônica \\
\hline 4-vinilpiridina & & Iônica, ligação de hidrogênio e transferência de carga \\
\hline 2-vinilpiridina & & Iônica, ligação de hidrogênio e transferência de carga \\
\hline 4-vinilimidazol & & Iônica, ligação de hidrogênio e coordenação de metais \\
\hline 1-vinilimidazol & & Iônica, ligação de hidrogênio e coordenação de metais \\
\hline Acrilamida & & ligação de hidrogênio \\
\hline
\end{tabular}

Agente de ligação cruzada

O ALC é responsável pelo controle da morfologia do MIP além de estabilizar os sítios de ligação e a estrutura mecânica do polímero (Cormack, Elorza, 2004). Salienta-se também que são requeridas altas proporções desse reagente (em relação ao MF) para garantir a porosidade do polímero (Cormack, Elorza, 2004). Diversos ALC têm sido usados (Figura 3) em impressão molecular com destaque para o etilenoglicol dimetacrilato devido à sua capacidade de formar polímeros térmica e mecanicamente estáveis e por possibilitar uma rápida transferência de massa durante a síntese.

\section{Solvente}

A principal função do solvente é dissolver os reagentes da síntese (MM, MF, ALC e IR) (Tarley, Sotomayor, Kubota, 2005). Entretanto, ele não pode interferir na formação do complexo MF-MM, o que pode resultar na formação de sítios de ligação pouco seletivos e em pequeno número. Dessa forma, o solvente adequado deve ser apolar, aprótico e de baixa constante dielétrica (e.g. clorofórmio) (Tarley, Sotomayor, Kubota, 2005). Por outro lado, é importante destacar que a capacidade térmica, bem como o volume do solvente (em relação aos demais reagentes), estão diretamente relacionados à estabilidade 
<smiles>C=C(C)C(O)OCCOC(=O)C(C)C</smiles>

etilenoglicol dimetacrilato<smiles>C=C(C)C(=O)OCCCCOC(=O)C(C)C</smiles>

tetrametileno dimetacrilato

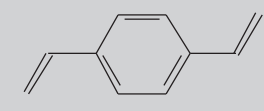

p-divinilbenzeno

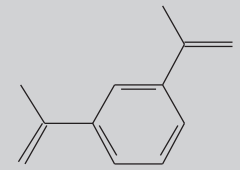

1,3-diisopropenil benzeno

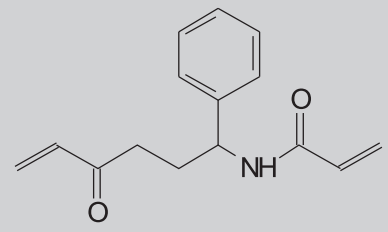

N,O-bisacriloil-L-fenilalaninol<smiles>C=CC(=O)Nc1cccc(NC(=O)C=C)c1</smiles>

2,6-bisacriloilamidopirina

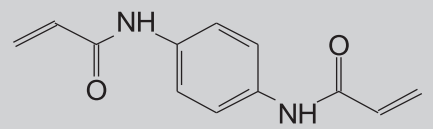

1,4-fenileno diacrilamina

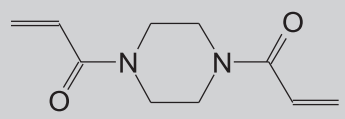

1,4-diacrilol

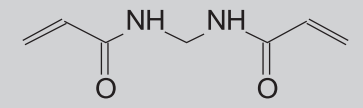

$\mathrm{N}, \mathrm{N}^{`}$-metileno bisacrilamida

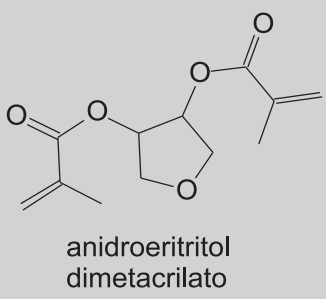<smiles>C=C(C)C(=O)Cl</smiles>

isopropilenobis(1,4-fenileno) dimetacrilato

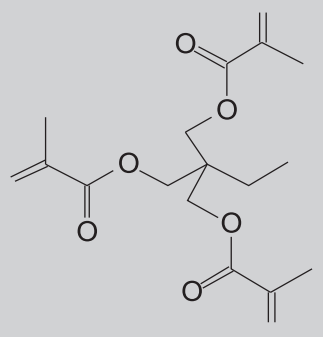

trimetilpropano trimetacrilato

FIGURA 3 - Estrutura química de alguns agentes de ligação cruzada, usualmente empregados na síntese de polímeros impressos molecularmente.

mecânica e a quantidade dos poros do MIP (Cormack, Elorza, 2004). Ressalta-se que a porosidade do MIP está estreitamente relacionada à sua capacidade de reconhecimento molecular por facilitar a difusão da MM nos sítios seletivos (Martín-Esteban, 2001).

\section{Iniciador radicalar}

A função do IR é criar radicais livres para possibilitar o início e a manutenção da reação de polimerização. Contudo, para o início da reação, é necessário algum estímulo físico como o aumento da temperatura ou a incidência de radiação UV. Esse estímulo é determinante na escolha do IR, pois outros reagentes da síntese (MM, MF, ALC) podem ser termo ou fotossensíveis (Cormack, Elorza, 2004). Além disso, em se tratando de ligações de hidrogênio entre a MM e o MF, sínteses conduzidas em baixa temperatura são preferencialmente requeridas (Cormack, Elorza, 2004). Alguns IR (Figura 4) têm sido empregados em síntese de MIP com destaque para o 2,2'azobisisobutironitrila, que é usado na maioria dos casos.

Além de todas as variáveis comentadas anteriormente, vale destacar a necessidade de eliminação do oxigênio do ambiente de síntese (purgando nitrogênio ou argônio, ou empregando banho ultra-som), porque esse produz um excesso de radicais que prejudicam a reação de polimerização (Tarley, Sotomayor, Kubota, 2005).

\section{MIP COMO SISTEMA DE LIBERAÇÃO CONTROLADA DE FÁRMACOS}

A tecnologia de impressão molecular tem sido amplamente empregada em diversas áreas, com destaque para a química analítica, principalmente na separação e concentração de vários analitos em diferentes amostras. Esta tecnologia, ainda, se encontra em fase inicial de desenvolvimento na área de DDS, sendo ausente e ligeiramente distante seu emprego clínico (Sellergren, Allender, 2005). Porém, o aumento progressivo no número de trabalhos voltados a essa aplicação de MIP (Figura 2) enfatiza seu caráter promissor, bem como evidencia o interesse de diversos grupos de pesquisas que trabalham com DDS.

O emprego de MIP em humanos requer a avaliação de diferentes parâmetros de risco inerentes à toxicidade dos polímeros, dos reagentes remanescentes da síntese e de seus produtos de degradação (Aydin et al., 2002; Fiume, 2002). Como exemplo, há de se enfatizar que as metodologias clássicas empregam solventes orgânicos como meio reacional, pois esses favorecem a formação de interações eletrostáticas e ligações de hidrogênio (Sellergren, Hall, 2001). Esses solventes podem causar sérios danos celulares e, por isso, são necessárias estratégias eficientes de lavagem dos polímeros até a obtenção de níveis de solventes 


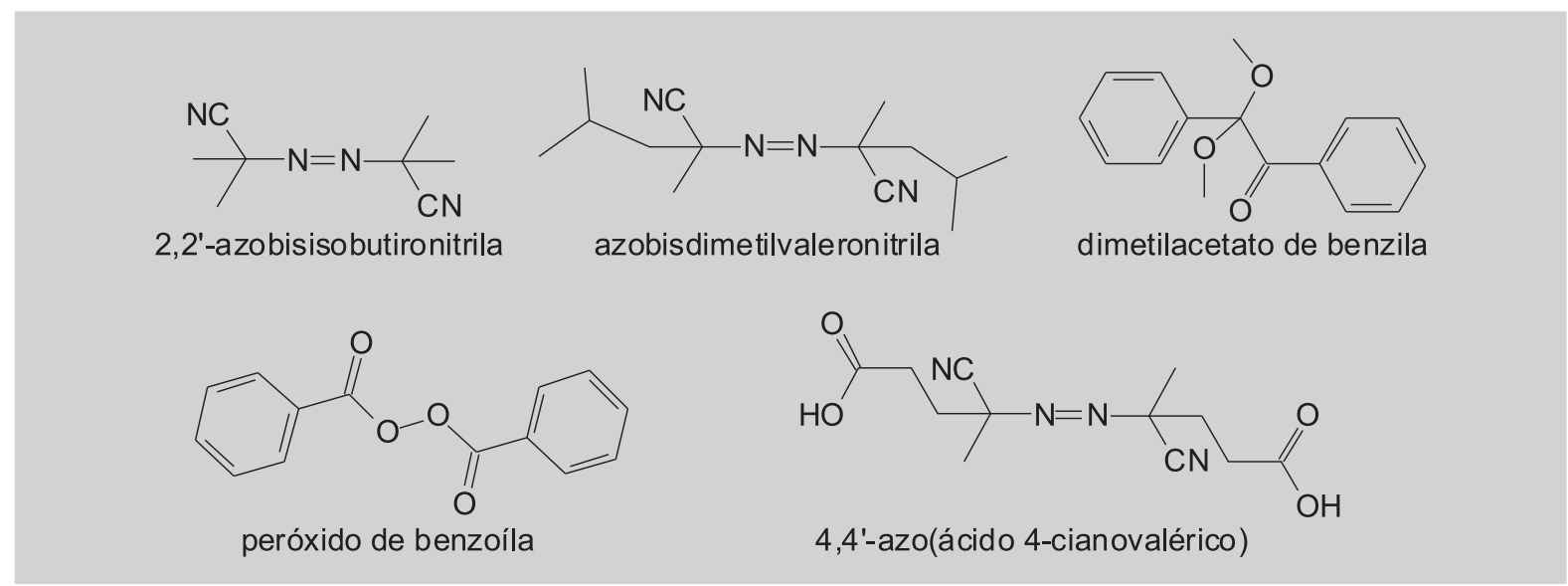

FIGURA 4 - Estrutura química dos iniciadores radicalares mais empregados na síntese de polímeros impressos molecularmente.

considerados não tóxicos. Em contrapartida, a busca por reagentes mais compatíveis com o sistema biológico tornase uma alternativa elegante para minimizar problemas de toxicidade. Nesse contexto, MIP aquosos (síntese em meio aquoso) são menos problemáticos e, por isso, são considerados uma forte tendência no campo de DDS.

Embora já esteja consolidado o emprego de hidrogéis como matrizes convencionais em DDS, a síntese de um MIP em meio aquoso ainda apresenta o problema atribuído à formação de interações fracas entre os MF e a MM, o que diminui a afinidade e a seletividade do polímero (Alvarez-Lorenzo, Concheiro, 2004).

O ponto principal que reforça o emprego de MIP em DDS é o seu potencial como sistemas inteligentes de liberação de fármacos. Esses sistemas permitem o início ou a variação da velocidade de liberação do fármaco em resposta a mudanças no ambiente no qual se encontra (ligação competitiva ou hidrólise das ligações MF-MM) ou a mudanças na estrutura tridimensional do polímero (mudança estereoquímica da estrutura polimérica, causando a liberação do fármaco) (AlvarezLorenzo, Concheiro, 2004; Cunliffe, Kirby, Alexander, 2005; Sellergren, Allender, 2005).

Com base no mecanismo que rege a liberação do fármaco, pode-se classificar os DDS em três classes: 1) velocidade contínua de liberação, 2) liberação por ativação modulada e 3) liberação controlada por "feedback" (Alvarez-Lorenzo, Concheiro, 2004). A seguir, essas classes são detalhadas e exemplificadas.

\section{Velocidade contínua de liberação}

Nessa classe de DDS, o fármaco é liberado a uma razão constante, ajustada para a manutenção da concentração plasmática em níveis terapêuticos. Salienta-se que a sua principal aplicação está voltada à liberação de fármacos de baixo índice terapêutico (e.g. barbitúricos, digoxina, teofilina). Esses fármacos apresentam uma faixa estreita entre a mínima concentração terapêutica e a mínima concentração na qual se observam efeitos indesejados.

Norell et al. (1998) avaliaram a cinética de liberação da teofilina a partir de um MIP, preparado com ácido metacrílico como MF (Vlatakis et al., 1993). O polímero apresentou boa seletividade, sendo capaz de se ligar preferencialmente à teofilina na presença de cafeína. Para os estudos de liberação foram empregadas diferentes massas de teofilina (dissolvidas em clorofórmio) para saturar os polímeros e estes foram posteriormente dialisados em tampão fosfato nos diferentes valores de $\mathrm{pH}$. O melhor resultado obtido foi aquele no qual se empregou pequena massa de teofilina (0,1 e 2,0 mg de teofilina por grama de MIP) em $\mathrm{pH}$ 7,0 , resultando em uma liberação sustentada por até $8 \mathrm{~h}$.

Suedee, Srichana e Rattananont (2002) avaliaram a liberação enantiosseletiva de misturas racêmicas de dois fármacos antiinflamatórios não-esteróides (ibuprofeno e cetoprofeno) e um fármaco $\beta$-bloqueador (propranolol). Os MIP foram preparados para os isômeros puros $S$-ibuprofeno, $S$-cetoprofeno e $R$-propranolol por meio da uma técnica de agregação e polimerização térmica (Haginaka, Sanbe, Takehira, 1999) e com ácido metacrílico como MF. Os estudos de liberação foram conduzidos por meio de ensaio de dissolução in vitro e posterior quantificação por cromatografia líquida de alta eficiência. Os resultados mostraram que o tempo de liberação foi maior (menor velocidade de liberação) para os respectivos isômeros empregados na síntese do MIP. Como exemplo, o $S$-ibuprofeno-MIP liberou o isômero $S$-ibuprofreno mais lentamente que o isômero $R$-ibuprofeno. Tal resultado denota que o isômero $S$ liga-se 
mais fortemente ao polímero em comparação ao isômero $R$. Também foi observado que a massa de fármaco em relação à massa de MIP (etapa de saturação do polímero) bem como o pH do meio possuem influência significativa no tempo de liberação. Assim, os autores propuseram um estudo para avaliar a liberação obtida em diferentes condições de pH. Os resultados mostraram que as porcentagens de liberação de $S$-ibuprofeno e $R$-propranolol de polímeros $S$-ibuprofeno-MIP e $R$-propranolol-MIP para pH 3, 0 foram de 0 e $99 \%$, respectivamente. Em pH 7,4, as porcentagens de liberação foram de $15 \%$ para $S$-ibuprofeno e $6 \%$ para $R$-propranolol.Assim, em uma situação in vivo, possivelmente o $R$-propranolol seria liberado no estômago enquanto o $S$-ibuprofeno no intestino (Suedee, Srichana, Rattananont, 2002).

Hiratani e Alvarez-Lorenzo (2002) sintetizaram lentes de contato dotadas de capacidade de reconhecimento molecular e avaliaram seu potencial na liberação controlada (in vitro) de timolol ( $\beta$-bloqueador usado no glaucoma). O MF empregado foi o ácido metacrílico e a polimerização foi feita com $N, N$-dimetilacrilamida e etilenoglicol dimetacrilato (ALC) em moldes pré-definidos. Uma lente controle também foi sintetizada nas mesmas condições, porém na ausência de timolol. Após a polimerização, as lentes foram lavadas e posteriormente imersas em $10 \mathrm{~mL}$ de solução aquosa de timolol (2 a $\left.64 \mu \mathrm{mol} \mathrm{L}^{-1}\right)$ para o armazenamento do fármaco. Estas foram, então, mergulhadas em uma solução $0,9 \%(\mathrm{~m} / \mathrm{v})$ de $\mathrm{NaCl}$ e a concentração de timolol foi periodicamente monitorada. Os resultados demonstraram que as lentes impressas para timolol (MIP) foram capazes de liberar quantidades gradativas do fármaco por até $24 \mathrm{~h}$, enquanto que as lentes controle (sintetizadas sem o timolol) liberaram o fármaco por um período de $8 \mathrm{~h}$. Em outro trabalho (Hiratani et al., 2005), os autores avaliaram a liberação in vitro de timolol pelas lentes de contato. Nesse caso, as lentes foram colocadas nos olhos de coelhos e a concentração de timolol foi monitorada periodicamente na lágrima dos animais. Os resultados mostraram que a lente conseguiu manter a concentração terapêutica de timolol na lágrima do coelho por até $90 \mathrm{~min}$. Cabe ressaltar que, com a administração convencional [ 1 gota $(50 \mathrm{~mL})$ de timolol $0,065 \% \mathrm{~m} / \mathrm{v}$ ], a concentração do fármaco encontrada na lágrima foi próxima de zero para tempos maiores que 15 min.

A eficiência da ação de alguns antibióticos está diretamente relacionada à manutenção de concentrações terapêuticas por longos e ininterruptos períodos de tempo. Nesse sentido, Alverez-Lorenzo et al. (2006) sintetizaram uma lente de contato-MIP para norfloxacino, com o emprego de ácido acrílico como MF. Os testes de liberação in vitro foram realizados mergulhando cada lente em uma solução de composição semelhante à lágrima e monitorando a concentração de norfloxacino liberada em função do tempo. Os resultados demonstraram que a lente de contatoMIP foi capaz de liberar norfloxacino por até $24 \mathrm{~h}$, enquanto a lente controle (lente sintetizada sem norfloxacino) liberou toda a quantidade de fármaco retida por um período de $10 \mathrm{~h}$.

Puoci et al. (2004) sintetizaram microesferas de MIP para sulfassalazina por meio da metodologia de polimerização por precipitação (Ye, Cormack, Mosbach, 1999; Wang et al., 2003), com ácido metacrílico como MF. $\mathrm{O}$ teste de liberação in vitro foi conduzido de forma a simular o ambiente do estômago e do intestino e de acordo com as recomendações da Farmacopéia Americana (USP XXII, 1990). Para tal, o MIP foi inicialmente saturado com sulfassalazina e, posteriormente, colocado em uma solução de $\mathrm{HCl} 0,1 \mathrm{~mol} \mathrm{~L}^{-1}$ (simulando o suco gástrico). Após 2 horas, adicionou-se tampão fosfato e ajustou-se o $\mathrm{pH}$ para 6,8 (simulando o fluido intestinal). Os resultados mostraram que o MIP liberou menos que $5 \%$ de sulfassalazina nas primeiras 2 horas $\left(\mathrm{HCl} 0,1 \mathrm{~mol} \mathrm{~L}^{-1}\right)$. Isso indica que o polímero pode funcionar como um protetor para fármacos que são notadamente degradados no estômago. Quando o pH foi alterado para 6,8, a liberação foi mantida por até $20 \mathrm{~h}$, corroborando a proposta inicial do trabalho.

\section{Liberação por ativação modulada}

Esses DDS são caracterizados por liberarem o fármaco por meio de estímulos físicos, químicos ou bioquímicos. Assim, tais estímulos, notadamente inerentes ao sistema biológico, podem desestabilizar as ligações do fármaco com o polímero por competição ou por hidrólise (Alvarez-Lorenzo, Concheiro, 2004). Por outro lado, também pode ocorrer um inchaço do polímero decorrente de transição de volume de fase e, conseqüentemente, o enfraquecimento das ligações que estabilizam o complexo.

Sreenivasan (1999) sintetizou um polímero capaz de liberar testosterona, em função da concentração de hidrocortisona do meio. A síntese foi feita empregando-se 2-hidroxi-etil-metacrilato como MF e radiação gama (Sreenivasan, 1997) para início e manutenção da polimerização. Após a síntese, os MIP foram lavados e recarregados (até saturação) com testosterona. A liberação foi avaliada empregando-se $100 \mathrm{mg}$ de MIP em $10 \mathrm{~mL}$ de água (tri-destilada) na ausência ou na presença de hidrocortisona. Os resultados mostraram que na ausência de hidrocortisona, o MIP liberou para o meio $28 \pm 3,46 \pm$ $2,61 \pm 1$ e $79 \pm 2 \mu \mathrm{g}$ de testosterona nos tempos de 1, 2 , 4 e $24 \mathrm{~h}$, respectivamente. Na presença de $50 \mu \mathrm{g} \mathrm{L}^{-1} \mathrm{de}$ hidrocortisona, o MIP liberou para o meio $23 \pm 3,166 \pm 4$ e $171 \pm 3 \mathrm{mg}$ de testosterona nos tempos de 1 , 2 e $4 \mathrm{~h}$, res- 
pectivamente. Dessa forma, pode-se observar a influência significativa da concentração de hidrocortisona na liberação de testosterona. Esse fato é certamente atribuído à competição entre as moléculas pelo mesmo sítio de ligação, decorrente de sua semelhança estrutural.

Karlsson, Andersson e Nicholls (2001) fizeram uma avaliação da ligação preferencial de diferentes anestésicos locais em um MIP para bupivacaína. O polímero foi sintetizado empregando ácido metacrílico como MF e a reação foi iniciada com radiação UV (366 nm). A competição dos anestésicos pelo MIP foi avaliada formando-se uma suspensão de MIP, estabilizada com Tween 20 e acrescida de bupivacaína e outros anestésicos locais. A suspensão foi incubada por $3 \mathrm{~h}$ a $23^{\circ} \mathrm{C}$ e centrifugada a $5000 \mathrm{~g}$ por $5 \mathrm{~min}$. Posteriormente, os anestésicos foram determinados no sobrenadante. Os resultados mostraram que a bupivacaína liga-se preferencialmente ao polímero, principalmente em meio aquoso. Em relação à competição pelos sítios, percebe-se a seguinte ordem de afinidade pelo MIP (facilidade de ligação): bupivacaína $>$ pentacaína $>$ ropivacaína $>$ eticaína $>$ mepivacaína. Dessa forma, pode-se pressupor que um MIP saturado com bupivocaína, libera o fármaco com maior facilidade na presença de pentacaína, devido à boa interação dessa última e o sítio de ligação do MIP.

Ye, Cormack e Mosbach (2001) propuseram uma metodologia para a obtenção de dois MIP, na forma de microesferas, que apresentam sítios seletivos a teofilina e $17-\beta$-estradiol, respectivamente. Os resultados mostraram que a teobromina e a cafeína foram capazes de deslocar a teofilina do sítio de ligação com o MIP. Da mesma forma, o 17- $\alpha$-estradiol e 17- $\alpha$-etinilestradiol também deslocaram o 17- $\beta$-estradiol do sítio de ligação com o MIP de 17- $\beta$ estradiol. Mais uma vez foi demonstrado o fenômeno da competição entre as moléculas com estruturas químicas semelhantes para o mesmo sítio de ligação.

Relativamente aos exemplos expostos anteriormente, deve-se enfatizar que uma molécula com estrutura química semelhante pode ocupar um sítio receptor de outra, mesmo que essa ligação seja estereoquimicamente menos favorável. Esse comportamento pode ser justificado pelas altas concentrações das moléculas no meio, que tendem a deslocar o equilíbrio no sentido de promover a ligação da molécula ao sítio receptor.

Um processo alternativo para modular a liberação de fármacos consiste na degradação progressiva da matriz. Esse processo pode ser induzido por condições extremas de pH ou pela presença de enzimas (Alvarez-Lorenzo, Concheiro, 2004). Uma aplicação importante está voltada àqueles fármacos facilmente degradados pela acidez estomacal. Assim, a matriz se mantém íntegra durante a passagem pelo estômago e se degrada na porção inicial do intes- tino, por ação de enzimas, ou pela ação do pH dessa parte do trato gastrintestinal.

Karmalkar, Kulkarni e Mashelkar (1997) sintetizaram um MIP (hidrogel) que apresentava um grupo imidazol próximo da ligação do fármaco (ácido $p$-aminobenzóico) com o polímero. A síntese foi feita empregando-se os MF 2-hidroximetil metacrilato, $N$-vinilimidazol e metacriloiletil- $p$-aminobenzoato, em diferentes proporções, e na presença de íons $\mathrm{Co}^{2+}$. Esses íons foram importantes porque aproximaram os MF $N$-vinilimidazol e metacriloiletil $p$-aminobenzoato formando um complexo coordenado mais estável. A liberação de ácido $p$ aminobenzóico (por hidrólise) foi estudada adicionando-se o polímero a uma solução de etanol-tampão fosfato em $\mathrm{pH}$ $8(40: 60 \mathrm{v} / \mathrm{v})$. O teor de ácido $p$-amino benzóico foi monitorado periodicamente e os resultados mostraram que o polímero manteve a liberação do fármaco por até 14 dias.

Outra maneira de promover liberação controlada de fármacos refere-se ao emprego de materiais sujeitos à modificação de volume mediante alterações do ambiente em que se encontram (Okano et al., 1990; Yuk, Bae, 1999). De forma geral, alterações de natureza físico-química tais como temperatura, $\mathrm{pH}$, força iônica, composição do solvente, campo elétrico, presença de luz ou de algumas moléculas (Hirokawa, Tanaka, 1984), são causas de mudanças estruturais significativas, que resultam em inchaço da matriz e enfraquecimento das ligações com o fármaco. A associação dessa técnica com a impressão molecular tem como principais vantagens a alta capacidade de armazenamento do fármaco e a possibilidade de controlar a velocidade de liberação mediante uma alteração físicoquímica (Alvarez-Lorenzo, Concheiro, 2004).

Alvarez-Lorenzo et al. (2001) sintetizaram um gel polimérico sensível à temperatura para a liberação de íons $\mathrm{Ca}^{2+}$ usando $N$-isopropilacrilamida e ácido metacrílico como MF, por meio de um processo de polimerização por radicais livres (Ricka, Tanaka, 1985). Após a síntese, o gel foi colocado em uma solução de $\mathrm{Ca}^{2+}\left(\mathrm{CaCl}_{2}, 8 \mu \mathrm{mol} \mathrm{L}{ }^{-1}-\right.$ $0,8 \mathrm{mmol} \mathrm{L}^{-1}$ ) a concentração do íon foi monitorada (após o equilíbrio) empregando-se um eletrodo íon-seletivo. Os resultados mostraram que o inchaço ou encolhimento do gel pode ser feito periodicamente mediante uma simples modificação de temperatura.

No mesmo contexto, o trabalho de Moritani e AlvarezLorenzo (2001) relata a síntese de um MIP (gel) com sítio seletivo a nitroisoftalato dissódico. Como MF foram empregados $N$-isopropilacrilamida, Imprinter-Q [MF a base de $N$ (3-(dimetilamina)propil)metacrilamida (Moritani, AlvarezLorenzo, 2001)] e $N, N$-metilenobis(acrilamida) em um processo de polimerização por radicais livres. Os géis foram, então, saturados com nitroisoftalato dissódico e colocados 
em uma solução aquosa. Verificou-se que quando a temperatura atingia $20{ }^{\circ} \mathrm{C}$, uma grande quantidade de nitroisoftalato dissódico era liberado para a solução aquosa. Contudo, quando a temperatura era elevada para $60^{\circ} \mathrm{C}$, uma fração considerável do nitroisoftalato dissódico se religava ao MIP, demonstrando a grande influência dessa variável. Segundo os autores, esse comportamento novo dos géis de $\mathrm{N}$-isopropilacrilamida nunca havia sido relatado. Cabe ressaltar que estes géis já vêm sendo explorados para a criação de matrizes inteligentes que liberam o fármaco mediante variações de temperatura (Chung, Yokoyama, Okano, 2000; Hoffman, 1987; Kim et al., 2000; Lee, Yen, 2000).

\section{Liberação controlada por feedback}

Em sistemas regulados por feedback, a liberação do fármaco depende da concentração de uma biomolécula reguladora (Alvarez-Lorenzo, Concheiro, 2004). Quando essa biomolécula atinge determinada concentração, a liberação é ativada. O fármaco, ao exercer sua ação no organismo, produz, como efeito, a diminuição da concentração da biomolécula ativadora e, conseqüentemente, o bloqueio no processo de liberação. Essa auto-regulação pode ser de grande valia em casos de diabetes Mellitus tipo 1, em que as doses de insulina administradas dependem diretamente da concentração de glicose no sangue. Nesse contexto, a avaliação de sistemas dotados de reconhecimento molecular apresenta-se como uma elegante alternativa na criação de DDS controlados por feedback (Hilt, Byrne, 2004; Miyata, Uragami, Nakamae, 2002; Sellergren, Allender, 2005).

Kataoka et al. (1999) e Uchimura et al. (2001) têm trabalhado com um hidrogel contendo o complexo boratoglicose, capaz de aumentar a sua hidratação dependendo da concentração de glicose, o que causa mudança na forma do gel e, conseqüentemente, modificação em sua capacidade de liberar fármacos. Esta propriedade está diretamente relacionada à concentração de glicose, uma vez que a ligação dessa molécula com o gel torna o mesmo mais hidrofílico. Os autores salientaram que esse tipo de gel pode ser usado adequadamente como uma válvula química para regular a liberação de insulina, como resposta às variações na concentração de glicose.

Embora atraente, o emprego de MIP como DDS controlado por feedback ainda se restringe a poucos trabalhos, talvez pela complexidade atribuída à formulação desses materiais. Por outro lado, o desenvolvimento de sensores para monitorar substâncias endógenas no sangue (e.g. glicose) é relativamente mais estudado, uma vez que a concentração dessas substâncias pode determinar a dose de um fármaco administrado em tratamentos como o do diabetes Mellitus tipo 1 e reposição hormonal. Esses sensores fornecem a concentra- ção da substância endógena, e o paciente administra a dose adequada do fármaco (Hillberg et al., 2005).

Chen et al. (1997) desenvolveram um sensor-MIP de $\alpha$-metil-d-glicose, que apresenta modificação proporcional do $\mathrm{pH}$ dependendo da concentração de glicose. Striegler $(2001,2002,2003)$ também avaliou um sensor para glicose que permite a ligação dessa molécula na faixa de $\mathrm{pH}$ de 5,5 a 7,5. Novos MF foram estudados, tais como diformato de [4-( $N$-vinilbenzil)dietilenotriamina) cobre(II)] ou dinitrato de [(dietilenotriamina) cobre(II)], e os resultados mostraram boa seletividade para glicose na presença de manose $\mathrm{e}$ galactose.

O acoplamento de sensores aos sistemas administração de fármacos, bem como a miniaturização desses dispositivos, podem resultar em microchips que funcionam como sistemas de auto-regulação controlados por feedback. Ressalta-se que estes dispositivos, intitulados de "microchips de diagnóstico e tratamento" são considerados como a linha mais avançada em sistemas auto-reguláveis, o que é reforçado pelo grande aumento do conhecimento inerente aos mesmos (Hilt, Byrne, 2004). Como exemplo, Santine Jr., Cima e Langer (1999) desenvolveram um sensor (microchip) de silicone em estado sólido que pode controlar a liberação de uma ou várias moléculas. $\mathrm{O}$ mecanismo de liberação é baseado na dissolução eletroquímica por uma membrana anódica fina, que cobre um micro-reservatório preenchido com o fármaco. O trabalho de Grayson et al. (2003) relata a construção de um microchip polimérico biodegradável para a liberação de dextrana, hormônio do crescimento humano e heparina. $\mathrm{O}$ dispositivo foi fabricado com membranas de diferentes massas moleculares de poli( $L$-ácido láctico) e poli $(D, L$-ácido láctico-co-glicólico) que cobriram o reservatório do fármaco. $\mathrm{O}$ dispositivo apresentou potencial para a liberação em pulsos por diferentes intervalos de tempo.

Com a integração de sensores (à base de MIP) em microchips de diagnóstico e tratamento, podem ser criados novos sistemas de liberação de fármacos. Esses dispositivos certamente apresentarão um controle mais refinado da liberação, inacessível com o emprego das técnicas convencionais, resultando em um acompanhamento mais detalhado da atividade terapêutica dos fármacos (Hilt, Byrne, 2004).

\section{TENDÊNCIAS E CONCLUSÕES}

O emprego de MIP em dispositivos de liberação controlada de fármacos ainda se restringe a poucos trabalhos, talvez pela complexidade inerente à criação de dispositivos eficientes e seguros. Contudo, principalmente a partir do ano 2000, percebe-se um aumento exponencial no número de artigos científicos (Figura 2), evidenciando o futuro sucesso de tal aplicação. 
Como tendência, acredita-se que três vertentes se destacam: i) melhorias na otimização das condições de síntese (principalmente a natureza e proporção do MF), empregando-se ferramentas como a modelagem computacional ou quimiometria, o que reduziria o consumo de reagentes, bem como tornaria tal otimização menos sujeita à condição de tentativa e erro (Nicholls et al., 2001); ii) síntese de MIP em meio aquoso, o que permitiria a obtenção de polímeros para moléculas instáveis ou insolúveis em solventes orgânicos, possibilitando o reconhecimento in vivo de moléculas específicas devido à sua maior compatibilidade com o sistema biológico; iii) dispositivos controlados por feedback, principalmente aqueles nos quais a matriz sofre modificação decorrente da presença de molécula endógena resultando na liberação do fármaco. Contudo, ressalta-se que ainda não foi explorado o emprego de MIP na construção de microchips de diagnóstico e tratamento. Porém, fundamentado nas características relevantes desses microchips relacionados ao controle refinado na liberação de fármacos e na seletividade dos MIP, tem-se como certa uma futura associação dessas tecnologias, na busca por DDS com perfis de liberação menos oscilantes.

\section{ABSTRACT \\ Molecular Imprinting: a promising strategy in matrices elaboration for drug delivery systems}

Biomolecular interactions (antigen-antibody, enzymesubstrate and drug-receptor) have been investigated due to their selective nature. Thus, since 1940, the search for synthetic materials presenting specific binding sites has been increasing. Nowadays, they are well established in different science areas such as pharmacy, analytical chemistry, biochemistry, among others, being the referred materials called molecularly imprinted polymers-MIP. Although the largest applications of MIP are found in the separations science field, few applications of these polymers have been reported as drug delivery systemsDDS. Such applications have been promising due to the feasibility of the MIP synthesis. However, the clinical use of the MIP as DDS is still not observed, probably due to its recent application, as well as extensive tests necessary for its approval as a new pharmaceutical form. In this way, this work aims to present the most recent progresses in the use of MIP as DDS, reinforcing the most significant aspects of this application (potentialities and limitations), as well as classifying and detailing such systems.

UNITERMS: Molecularly imprinted polymers. Drug delivery system.

\section{AGRADECIMENTOS}

Os autores agradecem à Fundação de Amparo à Pesquisa do Estado de São Paulo (FAPESP), ao Conselho Nacional de Desenvolvimento Científico e Tecnológico (CNPq), à Coordenação de Aperfeiçoamento de Pessoal de Nível Superior (CAPES) e à Financiadora de Estudos e Projetos (FINEP) pelo suporte financeiro.

\section{REFERÊNCIAS BIBLIOGRÁFICAS}

ALLENDER, C.J.; RICHARDSON, C.; WOODHOUSE, B.; HEARD, C.M.; BRAIN, K.R. Pharmaceutical applications for molecularly imprinted polymers. Int. J. Pharm., v.195, n.1-2, p. 39-43, 2000.

ALVAREZ-LORENZO, C.; CONCHEIRO, A. Molecularly imprinted polymers for drugs delivery. J. Chromatogr., $B$ : Anal. Technol. Biomed. Life Sci, v.804, n.1, p.231-245, 2004.

ALVAREZ-LORENZO, C.; GUNEY, O.; OYA, T.; SAKAI, Y.; KOBAYASHI, M.; ENOKI, T.; TAKEOKA, Y.; ISHIBASHI, T.; KURONA, K.; TANAKA, K.; WANG, G.; GROSBERG, A.Y. Reversible adsorption of calsium ions by imprinted temperature sensitive gels. J. Chem. Phys., v.114, n.6, p.2812-2816, 2001.

ALVAREZ-LORENZO, C.; YANEZZ, F.; BARREIROIGLESIAS, R.; CONCHEIRO, A. Imprinted soft contact lenses as norfloxacin delivery systems. J. Control. Release, v.113, n.3, p. 236-244, 2006.

ANDERSSON, L.; SELLERGREN, B.; MOSBACH, K. Imprinting of amino acid derivatives in macroporous polymers. Tetrahedron Lett., v.25, n.45, p.5211-5214, 1984.

ARSHADY, R.; MOSBACH, M. Synthesis of substrateselective polymers by host-guest polymerization, Macromol. Chem. Phys., v.182, n.2, p. 687-692, 1981.

AYDIN, O.; ATTILA, G.; DOGAN, A.; AYDIN, M.V.; CANACANKATAN, N.; KANIK, A. The effects of methyl methacrylate on nasal cavity, lung, and antioxidant system (an experimental inhalation study). Toxicol. Pathol., v.30, n.3, p.350-356, 2002. 
AZEVEDO, M.M.M. Nanoesfereas e a liberação controlada de fármacos. In: WORKSHOP DO CURSO: TÓPICOS ESPECIAIS EM QUÍMICA INORGÂNICA IV INTRODUÇÃO À NANOTECNOLOGIA: UM ENFOQUE QUÍMICO, 1, Campinas, 2002. Disponível em: <http://lqes.iqm.unicamp.br/images/ vivencia_lqes_monografias_marcelo_nanoesferas.pdf $>$. Acesso em: $0 \overline{8}$ maio 2007.

BERZELIUS, J. J. Jahresber. Chem., v.15, p.242-244, 1835.

CHEN, G.; GUAN, Z.; CHEN, C.; FU, L.; SUNDARESAN, V.; ARNALD, F.H. A glucose-sensing polymer. Nat. Biotechnol., v.15, n.4, p.354-357, 1997.

CHIEN, Y.W.; LIN, S. Optimisation of treatment by applying programmable rate-controlled drug delivery technology. Clin. Pharmacokinet., v.41, n.15, p. 1267-1300, 2002.

CHUNG, J.E.; YOKOYAMA, M.; OKANO, T. Inner core segment design for drug delivery control of thermoresponsive polymeric micelles. J.Control. Release, v.65, n.1-2, p.93-103, 2000.

CIARDELLI, G.; CIONI. B.; CRISTALLINI, C.; BARBANI, N.; SILVESTRI, D.; GIUSTI, P. Acrylic polymeric nanospheres for the release and recognition of molecules of clinical interest. Biosens. Bioelectron, v.20, n.6, p.1083-1090, 2004.

CORMACK, P.A.G.; ELORZA, A.Z. Molecularly imprinted polymers: synthesis and characterization. J. Chromatogr., B: Anal. Technol. Biomed. Life Sci., v.804, n.1, p.173182, 2004.

CUNLIFFE. D.; KIRBY, A.; ALEXANDER, C. Molecularly imprinted drug delivery systems. Adv. Drug Deliv. Rev., v.57, n.12, p.1836-1853, 2005.

DICKEY, F.H. The preparation of specific adsorbents. Proc. Natl. Acad. Sci., v.35, n.5, p.227-229, 1949.

DURÁN, N.; DEAZEVEDO, M.M. O que é nanotecnologia? Atualidades e perspectivas. Disponível em: $<$ http:// www.ifi.unicamp.br/extensao/downloads/ nanobiotecnologia. doc >. Acesso: 15 jun. 2007.

FIUME, M.Z. Final report on the safety assessment of acrylates copolymer and 33 related cosmetic ingredients. In. J. Toxicol., v.21, n.3, p.1-50, 2002.
GLAD, M.; REINHOLDSSON, P.; MOSBACH, K. Molecularly imprinted composite polymers based on trimethylolpropane trimethacrylate (TRIM) particles for efficient enantiomeric separations. React. Poly., v.25, n.1, p.47-54, 1995.

GRAYSON, A.C.R.; CHOI, I.; TYLER, B.M.; WANG, P.P.; BREM, H.; CIMA, M.J.; LANGER, R. Multi-pulse drug delivery from a resorbable, polymeric microchip device. Nat. Mater., v.2, n.11, p.767-772, 2003.

HAGINAKA, J. Monodispersed, molecularly imprinted polymers as affinity-based chromatography media. $J$. Chromatogr., B: Anal. Technol. Biomed. Life Sci, v.866, n.1-2, p.3-13, 2008.

HAGINAKA, J.; SANBE, H.; TAKEHIRA, H. Uniformsized molecularly imprinted polymer for (S)-ibuprofen retention properties in aqueous mobile phases. $J$. Chromatogr., A., v.857, n.1-2, p.117-125, 1999.

HILLBERG, A.L.; BRAIN, K.R.; ALLENDER, C.J. Molecular imprinted polymer sensors: implications for therapeutics. Adv. Drug Deliv. Rev., v.57, n.12, p.18751889,2005

HILT, J.Z.; BYRNE, M.E. Configurational biomimesis in drug delivery: molecular imprinting of biologically significant molecules. Adv. Drug Delivery Rev., v.56, n.11, p.1599-1620, 2004.

HIRATANI, H.; ALVAREZ-LORENZO, C. Timolol uptake and release by imprinted soft contact lenses made of N,Ndimethylacrylamine and methacrylic acid. J. Control. Release, v.83, n.2, p.223-230, 2002.

HIRATANI, H.; FUJIWARA, A.; TAMIYA, Y.; MIZUTANI, Y; ALVAREZ-LORENZO, C. Ocular release of timolol from molecularly imprinted soft contact lenses. Biomaterials, v.26, n.11, p.1293-1298, 2005.

HIROKAWA, Y.; TANAKA, T. Volume phase transition in a nonionic gel. J. Chem. Phys., v.81, n.12, p.6379-6380, 1984.

HOFFMAN, A.S. Applications of thermally reversible polymers and hydrogels in therapeutics and diagnostics. J. Control. Release, v.6, n.1, p.297-305, 1987. 
JANTARAT, C.; TANGTHONG, N.; SONGKRO, S.; MARTIN, G.P.; SUEDEE, R. S-Propranolol imprinted polymer nanoparticle-on-microsphere composite porous cellulose membrane for the enantioselectively controlled delivery of racemic propranolol. Int. J. Pharm., v.349, n.1-2, p.212-225, 2008.

KAPARISSIDES, C.; ALEXANDRIDOU, S.; KOTTI, K.; CHAITIDOU, S. Recent advances in novel drug delivery systems. J. Nanotechynol. Online, v.2, p.1-11, 2006.

KARLSSON, J.G.; ANDERSSON, L.I.; NICHOLLS, I.A. Probing the molecular basis for ligand-selective recognation in molecularly imprinted polymers for the local anesthetic bupivacaine. Anal. Chim. Acta, v.435, n.1, p.57-64, 2001.

KARMALKAR, R.N.; KULKARNI, M.G.; MASHELKAR, R.A. Pendent chain linked delivery systems: II. Facile hydrolysis through molecular imprinting effects. $J$. Control. Release, v.43, n.2-3, p.235-243, 1997.

KATAOKA, K.; MIYAZAKI, H.; BUNYA, M.; OKANO, T.; SAKURAI, Y. On-off regulation of insulin-release by totally synthetic polymer gels responding to external glucose concentration. Polym. Prepr., Abstracts of Papers of the American Chemical Society, v.217, n.165-Poly, p.U564-U564, 1999.

KHAJEH, M.; YAMINI, Y.; GHASEMI, E.; FASIHI, J.; SHAMSIPUR, M. Imprinted polymer particles for selenium uptake: Synthesis, characterization and analytical applications. Anal. Chim. Acta, v.581, n.2, p.208-213, 2007.

KIM, I.S.; JEONG, Y.I.; CHO, C.S.; KIM, S.H. Core-shell type polymeric nanoparticles composed of poly $(L$-lactic acid) and poly( $\mathrm{N}$-isopropylacrylamide. Int. J. Pharm., v.211, n.1-2, p.1-8, 2000.

LEE, W.F.; YEN, S.H. Thermoreversible hydrogels. XII. Effect of the polymerization conditions on the swelling behavior of the N-isopropylacrylamide gel. J. Appl. Polym. Sci., v.78, n.9, p.1604-1611, 2000.

LIMBIRD, L.E. The Receptor Concept: A Continuing Evolution. Mol. Interv., v.4, p.326-336, 2004.
MAGALHÃES, C.S., GARCIA, J.S.; LOPES, A.S.; FIGUEIREDO, E.C.; ARRUDA, M.A.Z. Strategies for sample preparation focusing on biomolecules determination/caracterization In: ARRUDA, M.A.Z. (Eds.). Trends in sample preparation. New York: Nova Science Publishers, 2007. cap.9, p.245-288.

MARTÍN-ESTEBAN, A. Molecularly imprinted polymers: new molecular recognation materials for selective solidphase extraction of organic compounds. Fresenius $J$. Anal. Chem., v.370, n.7, p.795-802, 2001.

MATSUI, J.; OKADA, M.; TSURUOKA, M.; TAKEUCHI, T. Solid-phase extraction of a triazine herbicide using a molecularly imprinted synthetic receptor. Anal. Commun., v.34, n.3, p.85-87, 1997.

MAYES, A.G.; MOSBACH, K. Molecularly imprinted polymer beads: suspension polymerization using a liquid perfluorocarbon as the dispersing phase. Anal. Chem., v.68, n. 21, p.3769-3774, 1996.

MIYATA, T.; URAGAMI, T.; NAKAMAE, K. Biomoleculesensitive hydrogels. Adv. Drug Del. Rev., v.54, n.1, p.7998, 2002.

MORITANI, T.; ALVAREZ-LORENZO, C. Conformational imprinting effect on stimuli-sensitive gels made with an “imprinter" monomer. Macromolecules, v.34, n.22, p.7796-7803, 2001.

NICHOLLS, I.A.; ADBO, K.; ANDERSSON, H.S.; ANDERSSON, P.O.; ANKARLOO, J.; HEDINDAHLSTROM, J.; JOKELA, P.; KARLSSON, J.G.; OLOFSSON, L.; ROSENGREN, J.; SHORAVI, S.; SVENSON, J.; WIKMAN, S. Can we rationally design molecularly imprinted polymers? Anal. Chim. Acta, v.435, n.1, p.9-18, 2001.

NORELL, M.C.; ANDERSSON, H.S.; NOCHOLLS, I.A. Theophylline molecularly imprinted polymer dissociation kinetics: a novel sustained realease drug dosage mechanism. J. Mol. Recog., v.11, n.1-6, p.98-102, 1998.

OKANO, T.; BAE, Y.H.; JACOBS, H.; KIM, S.W. Thermally on-off switching polymers for drug permeation and release. J. Control. Release, v.11, n.1-3, p.255-265, 1990. 
PAULING, L.J. A Theory of the structure and process of formation of antibodies. J. Am. Chem. Soc., v.62, n.10, p.2643-2657, 1940.

PHILIP, J.Y.N.; BUCHWEISHAIJA, J.; MKAYULA, L. L.; YE, L. Preparation of molecularly imprinted polymers using anacardic acid monomers derived from cashew nut shell liquid. J. Agric. Food Chem., v.55, n.22, p.88708876, 2007.

PUOCI, F.; IEMMA, F.; CIRILLO, G.; PICCI, N.; MATRICARDI, P.; ALHAIQUE, A. Molecularly Imprinted Polymers for 5-Fluorouracil Release in Biological Fluids. Molecules, v.12, n.4, p.805-814, 2007

PUOCI, F.; IEMMA, E.; MUZZALUPO, R.; SPIZZIRRI, U.G.; TROMBINO, S.; CASSANO, R.; PICCI, N. Spherical Molecularly Imprinted Polymers (SMIPs) via a Novel Precipitation Polymerization in the Controlled Delivery of Sulfasalazine. Macromol. Biosc., v.4, n.1, p.22-26, 2004.

RAMSTRÖM, O.; ANDERSSON, L.I.; MOSBACH, K. Recognition sites incorporating both pyridinyl and carboxy functionalities prepared by molecular imprinting. J. Org. Chem., v.58, n.26, p.7562-7564, 1993.

RICKA, J.; TANAKA, T. Phase transition in ionic gels induced by copper complexation. Macromol., v.18, n.1, p.83-85, 1985.

SANTINI Jr., J.T.; CIMA, M.J.; LANGER, R. A controlledrelease microchip. Nature, v.397, p.335-338, 1999.

SELLERGREN, B.; ALLENDER, C.J. Molecularly imprinted polymers: Abridge to advanced drug delivery. Adv. Drug Delivery Rev., v.57, n.12, p.1733-1741, 2005.

SELLERGREN, B.; HALL, A. J. Fundamental aspects on the synthesis and characterisation of imprinted network polymers; In: SELLERGREN, B. (Ed.). Molecularly imprinted polymers: Man-made mimics of antibodies and their applications in analytical chemistry. Amsterdam: Elsevier, 2001. cap.2, p. 21-57.

SELLERGREN, B.; LEPISTÖ, M.; MOSBACH, K. Highly Enantioselective and substrate-selective polymers obtained by molecular imprinting utilizing noncovalent interactions. NMR and chromatographic studies on the nature of recognition. J. Am. Chem. Soc., v.110, n.17, p.5853-5860, 1988.
SREENIVASAN, K. Imparting cholesterol recognition sites in radiation polymerised poly(2-hydroxyethyl methacrylate) by molecular imprinting. Polym. Int., v.42, n.2, p.169-172, 1997.

SREENIVASAN, K. On the aplication of molecularly imprinted poly(HEMA) as a template responsive realise system. $J$. Appl. Polym, Sci., v.71, n.11, p.1819-1821, 1999.

STRIEGLER, S. Selective discrimination of closely related monosaccharides at physiological $\mathrm{pH}$ a polymeric receptor. Tetrahedron, v.57, n.12, p.2349-2354, 2001.

STRIEGLER, S. Investigation of disaccharide recognition by molecularly imprinted polymers. Bioseparation, v.10, n.6, p.307-314, 2002.

STRIEGLER, S. Carbohydrate recognition in cross-linked sugar-templated poly(acrylates). Macromol., v.36, n.4, p.1310-1317, 2003.

SUEDEE, R.; SRICHANA, T.; RATTANANONT, T. Enantioselective release of contolled delivery granules based on molecularly imprintd polymers. Drug Delivery, v.9, n.1, p.19-30, 2002.

TARLEY, C.R.T.; SOTOMAYOR, M.P.T.; KUBOTA, L.T. Polímeros Biomiméticos em Química Analítica. Parte 1: Preparo e Aplicações de MIP (Molecularly Imprinted Polymers) em Técnicas de Extração e Separação. Quim. Nova, v.28, n.6, p.1076-1086, 2005.

THE UNITED STATES PHARMACOPEIA. 24. ed. Rockville: United States Pharmacopeial Convention, 2000. p.1577.

UCHIMURA, E.; OTSUKA, H.; OKANO, T.; SAKURAI, Y.; KATAOKA, K. Totally synthetic polymer with lectinlike function: induction of killer cells by the copolymer of 3-acrylamidophenilboronic acid with n,ndimethylacrylamide. Biotechnol. Bioeng., v.72, n.3, p.307-314, 2001.

ULUBAYRAM, K.; TUNC, Y.; BAYKARA, E.; Molecularly imprinted acrylic-based microspheres for colonic delivery of 5-aminosalicylic acid. J. Optoelectron. Adv. Mater., v.9, n.11, p.3479-3483, 2007.

VLATAKIS, G.; ANDERSSON, L.I.; MÜLLER, R.; $\mathrm{MOSBACH}, \mathrm{K}$. Drug assay using antibody mimics made by molecularly imprinting. Nature, v.361, p.645-647, 1993. 
WANG, J.F.; CORMARCK, P.A.G.; SHERRINGTON, D.C.; KHOSHDEL, E. Monodisperse, molecularly imprinted polymer microspheres prepared by precipitation polymerization for affinity separation applications. Angew. Chem., v.42, n.43, p.5336-5338, 2003.

WANG, X.B.; DING, X.B.; ZHENG, Z.H.; HU, X.H.; CHENG, X.; PENG, Y.X. Magnetic molecularly imprinted polymer particles synthesized by suspension polymerization in silicone oil. Macromol. Rapid Commun., v.27, n.14, p.1180-1184, 2006.

WHITCOMBE, M.J.; RODRIGUEZ, M.E.; VILLAR, P.; VULFSON, E.N. A new method for the introduction of recognition site functionality into polymers prepared by molecular imprinting - synthesies and characterization of polymeric recptors for cholesterol. J. Am. Chem. Soc., v. 117, n. 27, p. $7105-7111,1995$.

WOLMAN, F.J.; SMOLKO, E.E.; CASCONE, O.; GRASSELLI, M. Peptide imprinted polymer synthesized by radiation-induced graft polymerization. React. Funct. Polym. v.66, n.11, p.1199-1205, 2006.
WULFF, G.; SARHAN, A. Über die Anwendung von enzymanalog gebauten Polymeren zur Racemattrennung, Angew. Chem., v.84, n.8, p. 364, 1972.

YE, L.; CORMACK, P.A.G.; MOSBACH, K. Molecularly imprinted monodisperse microspheres for competitive radioassay. Anal. Commun, v.36, n. 2, p.35-38, 1999.

YE, L.; CORMACK, P.A.G.; MOSBACH, K. Molecular imprinting on microgel spheres, Anal. Chim. Acta, v.435, n.1, p.187-196, 2001.

YILMAZ, E.; RAMSTRÖM, O.; MÖLLER, P.; SANCHEZC, D.; MOSBACHA, K. A facile method for preparing molecularly imprinted polymer spheres using spherical silica templates. J. Mater. Chem., v.12, p.15771581, 2002.

YOSHIMATSU, K.; REIMHULT, K.; KROZER, A.; MOSBACH, K.; SODE, K.; YE, L. Uniform molecularly imprinted microspheres and nanoparticles prepared by precipitation polymerization: The control of particle size suitable for different analytical applications. Anal. Chim. Acta, v.584, n.1, p.112-121, 2007.

YUK, S.H.; BAE, Y.H. Phase-transition polymers for drug delivery. Crit. Rev. Ther. Drug Carrier Syst., v.16, n.4, p.385-423, 1999.

Recebido para publicação em 24 de agosto de 2007 Aceito para publicação em 06 de julho de 2008 